\title{
How Failure Leads to Learning among Nascent Entrepreneurs? The Evidence of Entrepreneurial Failure and Its Relationship to Entrepreneurial Learning
}

\author{
Hafiz Rahman', Eri Besra1, and Nurhayati \\ ${ }^{1}$ Department of Management, Faculty of Economics, Universitas Andalas \\ ${ }^{2}$ Department of Business Administration, Politeknik Negeri Padang
}

Corresponding Author:

Hafiz Rahman

hafizrahman@eb.unand.ac.id

Received: 30 December 2019 Accepted: 29 January 2020 Published: 6 February 2020

Publishing services provided by Knowledge E

(c) Hafiz Rahman et al. This article is distributed under the terms of the Creative Commons Attribution License, which permits unrestricted use and redistribution provided that the original author and source are credited.

Selection and Peer-review unde the responsibility of the 6 th ICOEN 2019 Conference Committee.

\begin{abstract}
This paper investigates and examines the relationship between entrepreneurial failure and entrepreneurial learning that can be absorbed by nascent entrepreneurs. It also reveals the possible forms of learning that happen to nascent entrepreneurs as an outcome of failure. A quantitative study with relational approach with 180 failed nascent entrepreneurs in Padang, Indonesia was undertaken as the research method and study context. Data and information were collected by using a questionnaire (offline and online) as the research instrument. Statistical protocol in terms of validity and reliability tests as well as hypothesis testing, using SPSS 23 as the statistical tool were operated to analyze the data. The study found that entrepreneurial failure has significantly influenced [a] entrepreneurial learning of nascent entrepreneurs in the context of the study, [b] the ability to detect errors in business, as well as [c] error correction by nascent entrepreneurs. The study also reveals the fact that the serial entrepreneurship process occurs for nascent entrepreneurs in the context of study.
\end{abstract}

Keywords: entrepreneurial failure, entrepreneurial learning, nascent entrepreneurs, error detection, error correction

\section{Introduction}

The vast majority of concept in entrepreneurial failure considered that failure is an event in entrepreneurs' entrepreneurial journey, [1]. Based on this consideration, scholars have further identified possible factors that may cause entrepreneurial failure, for example, [a] psycho-economic factors, [2,b] opportunistic behavior [3], etc. It is believed and viewed that the mixture of entrepreneurs' internal and external circumstances have been the major cause of entrepreneurial failure. There were also studies and researches that focused on the analysis to the impact of entrepreneurial failure to entrepreneurs, (see the studies and researches from, for example, [4]; [5]; [6], and [7]. In a study to identify impact of entrepreneurial failure, [8] mentioned that entrepreneurial failure creates social 
construction where the process of individual psychology in terms of [a] the existence of emotional processes and [b] the cognitive process to justify every action, exists.

The presence of the impact of entrepreneurial failure in entrepreneurship has become a major and important discussion for years. Scholars believed that failure will be beneficial for entrepreneurs during their entrepreneurial journey to reach entrepreneurial success. [9] stated that failure would become a fundamental learning experience in entrepreneurship, in which the process will bring three main possible outcomes: [a] opportunity recognition, [b] exploitation of opportunities, and [c] interpersonal relations, [10]. [11] have previously mentioned that failure may be used as an important learning opportunities that can be benefited by entrepreneurs to reach success. Meanwhile, [12] viewed that failure could improve process reliability, reduce failure-related costs, and could also improve the composition of the portfolio of projects through trial and error learning.

Despite scholars suggested that failure will lead entrepreneurs to learn something from that failure, however, there is no such a guarantee that entrepreneurs would be willing to learn something from failures they have made. This has strengthened by the opinion from [12] who stated that failure cannot always be beneficial for entrepreneurs. It only 'can help' entrepreneurs to learn without any guarantee to gain benefits from it. [12] further stated that the failure can help entrepreneurs to see/recognize opportunity. However, without any efforts to exploit that opportunity, the maximum benefits of learning from failure cannot be guaranteed. Apart from that, there is an evidence of the presence of motivational obstacles as well as cognitive obstacles that will hinder entrepreneurs to learn from failures, [13]. This means that entrepreneurs, who have experienced failure, may also be fail again -- if they psychologically refuse to learn from their previous failures and take no-action to exploit the result of learning from failure. This will be the research gap that should be considered if we would like to analyse more about failure and its impact to possibilities and intentions to learn.

Other gap is related to few empirical investigations to broaden our understanding about how entrepreneurial failure could be transformed into learning experience by entrepreneurs, [9]. Based on our previous studies in entrepreneurial failure, we then asked ourselves the following: [a] is there any impact of failure experienced by the failed nascent entrepreneurs to the possibility of individual learning in entrepreneurship?, and [b] if there are chances to learn, what could nascent entrepreneurs learn from the failure they have experienced with?

Therefore, this paper centers its focus and contributes to the discussion and debate in examining and elaborating the presence of entrepreneurial failure within 
nascent entrepreneurs. The objective of the study is further defined i.e. to investigate the relationship between entrepreneurial failure and individual learning by nascent entrepreneur and to reveal the possible forms of learning that occur to nascent entrepreneurs as an outcome of failure. The concepts of entrepreneurial failure from [2] as well as [14] and the concepts of entrepreneurial learning from [15] and [16] and [17] are used as the major and solid theoretical basis/foundation in this study. A specific analysis is focused on nascent entrepreneurs, as we believe that they are parties who are very fragile in experiencing entrepreneurial failure. Further, this study uses nascent entrepreneurs in Padang, Indonesia who have experienced entrepreneurial failure during their entrepreneurial journey as its research context.

The study argues that there is a positive and significant relationship between the presence of entrepreneurial failure and the improvement of individual learning by nascent entrepreneurs. It also finds the possible types of learning and learning mechanisms that can be absorbed by nascent entrepreneurs after they have experienced failure, and proves that the process of serial entrepreneurship occurs to nascent entrepreneurs. We consider those three findings as the significant contribution of this study to the research and study in entrepreneurship.

\section{Method and Framework}

\subsection{Method}

The study is a quantitative study with relational approach, and was undertaken with 180 failed nascent entrepreneurs in Padang, Indonesia. Samples were appointed based on the purposive sampling technique, based on the following criteria, [a] be in the age between 18 -- 30 years old, and [b] have previously experienced entrepreneurial failure. Sample is gender neutral and is regardless the level of education. Each variable is defined and further, dimensions of each variable are identified.

Data and information were collected by using the questionnaire as a cross-sectional cohort data. The questionnaire is in Indonesian language and was disseminated in two ways: [a] through online form, and [b] through offline/paper based questionnaire. In total, the questionnaire contains sixty four questions, which in detail is described as the following: [a] eight questions for the variable of entrepreneurial failure, [b] sixteen questions for the construct of outcomes of learning, [c] twenty questions for the construct of error detection, and [d] twelve questions for the construct of error correction. 
We use the content framework (Figure 2) to show the core of our work in the study. To put this framework in operation, we further determined the operational definition of each variable which is further used as the guidelines to quantitatively analyze all variables. Operational definition of variables in this study is further stated and shown as in the table 1.

TABLE 1: Operational Definition of the Variables.

\begin{tabular}{|c|c|c|c|}
\hline No & Variables & Concept of Variables & Dimension of the Variables \\
\hline 1 & $\begin{array}{l}\text { Entrepreneurial } \\
\text { Failure }\end{array}$ & $\begin{array}{l}\text { Entrepreneurial failure is a } \\
\text { psycho-economic phenomenon } \\
\text { which will lead entrepreneurs to } \\
\text { undertake error actions to allocate } \\
\text { resources and will result further } \\
\text { consequence, in terms of } \\
\text { psychological situation in the form of } \\
\text { disappointment, Smida and Khelil } \\
\text { (2010) }\end{array}$ & $\begin{array}{l}\text { [a] Emotive factor } \\
\text { [b] Voluntaristic factor } \\
\text { [c] Deterministic factor }\end{array}$ \\
\hline 2 & $\begin{array}{l}\text { Entrepreneurial } \\
\text { Learning }\end{array}$ & $\begin{array}{l}\text { Entrepreneurial learning is triggered } \\
\text { by the negative feedback, } \\
\text { expressed in undesirable or } \\
\text { unexpected outcomes of certain } \\
\text { actions. Consequently, errors made } \\
\text { by entrepreneurs are likely to trigger } \\
\text { learning because negative } \\
\text { outcomes tend to be more salient to } \\
\text { entrepreneurs than positive ones, } \\
\text { (Petkova, 2008) }\end{array}$ & $\begin{array}{l}\text { [a] error detection } \\
\text { [b] error correction } \\
\text { [c] Outcomes of failure }\end{array}$ \\
\hline
\end{tabular}

Source: conception of the authors, adopted from Smida and Khelil (2010) and Petkova (2008)

Relational analysis between variables is used to test the hypothesis with the support of SPSS 23 as the statistical tool. We choose relational analysis as the method of analysis based on the consideration that it can combine factor analysis of the study and can analyze the structural relationship between variables. The use of relational analysis is reasonable because the objective of our study is to examine the relationship between the presence of entrepreneurial failure and entrepreneurial learning, with particular analysis to the forms of possible learning outcome that would be gained by entrepreneurs.

\subsection{Framework}

In this part, we show the framework of our study in order to give an insight about how we conducted our study and how we focus ourselves in elaborating, examining and discussing variables and dimension of failure and learning. It also shows the way we 
analyze data and information collected during the field study. Content framework of this study is shown as in the Figure 1 below.

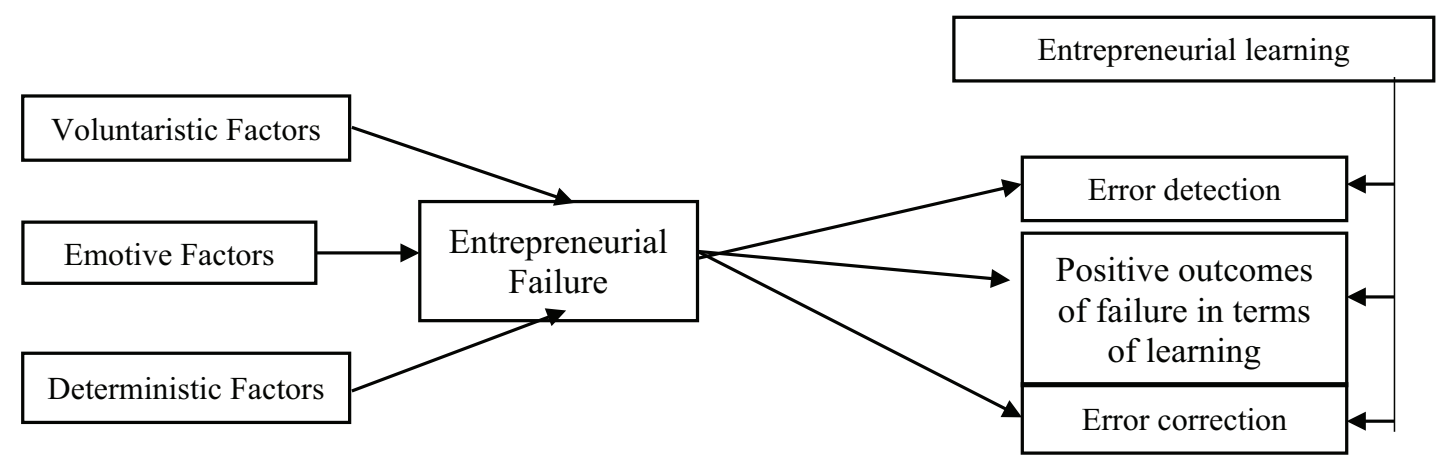

Figure 1: The content framework of the study (Source: conception of the authors, adopted from [2], [15], [18], [17], and [11]).

As other scholars and refer to Figure 2 above, we also believe that there is a direct influence of entrepreneurial failure, which is formed from [a] voluntaristic factors, [b] emotive factors and [c] deterministic factors of individuals on entrepreneurial learning. The major hypotheses that we examine in this paper consists of the main questions; what kind of entrepreneurial learning that nascent entrepreneurs can get after they experienced failure. For this exploration, we map it into three possibilities: [1] outcomes of failure in terms of learning, [2] error detection, and [3] error correction.

\section{Results}

The first task in this study is to examine and to expose the demographic profiles of research sample which are divided into two categories: [a] personal profile (includes gender, age, level of education and age when first started a business), and [b] business profile (includes the current business and number of experiencing failure). The major intention in describing the profiles of our sample is to prove that descriptively, they fit with sampling criteria as previously stated in the methodology part of this paper. The profile of our sample is shown in integrated tables as in the table 2 and 3.

Table 2 shows that demographically, respondents of the study are dominated by those who are [a] male, [b] in the age between 21 and 25 years old, and [c] having undergraduate education background. Those figures prove that our sample is categorized as nascent entrepreneurs, especially in terms of their age. Table 1 also shows that the majority of nascent entrepreneurs that we appointed as the research sample are those who first started their business during the age of 18-20 years old. Meanwhile, the business profile of our sample is shown as in the table 3 below. 
TABLE 2: Sample Profile of the Study (Personal Profile).

\begin{tabular}{|c|c|c|c|c|}
\hline Category & Characteristic & $\begin{array}{l}\text { Number of } \\
\text { Sample }\end{array}$ & Percentage (\%) & Valid Percent \\
\hline \multirow[t]{2}{*}{ Gender } & Male & 105 & 58.3 & 58.3 \\
\hline & Female & 75 & 41.7 & 100.0 \\
\hline \multirow[t]{3}{*}{ Age (years) } & $18-20$ & 16 & 8.9 & 8.0 \\
\hline & $21-25$ & 90 & 50.0 & 58.9 \\
\hline & $26-30$ & 74 & 41.1 & 100.0 \\
\hline \multirow[t]{3}{*}{ Level of Education } & $\begin{array}{l}\text { Elementary \& } \\
\text { Junior High } \\
\text { School }\end{array}$ & 1 & 0.6 & 0.6 \\
\hline & $\begin{array}{l}\text { Senior High } \\
\text { School }\end{array}$ & 52 & 28.9 & 29.5 \\
\hline & Undergraduate & 127 & 70.5 & 100.0 \\
\hline \multirow{4}{*}{$\begin{array}{l}\text { Age when first } \\
\text { starting a } \\
\text { business (years) }\end{array}$} & $18-20$ & 80 & 44.4 & 44.4 \\
\hline & $21-23$ & 78 & 43.3 & 87.8 \\
\hline & $24-26$ & 19 & 10.6 & 98.3 \\
\hline & $27-30$ & 3 & 1.7 & 100.0 \\
\hline
\end{tabular}

Source: Survey data, processed

The next and a bigger task in this study is to examine the presence of entrepreneurial failure and its relationship with entrepreneurial learning, which consists of three constructs [a] outcomes of failure in terms of the forms of learning, [b] error detection, and $[c]$ error correction in business, and further, to identify the possibility of the serial entrepreneurship within the failed nascent entrepreneurs. We undertake relational analysis with the support of SPSS 23 as the statistical tool to examine the relationship between entrepreneurial failure and the three constructs of entrepreneurial learning. Meanwhile, to identify the serial entrepreneurship process, we use the descriptive statistical analysis in terms of cross-tabulation analysis between the demographic profile of respondents/samples (based on education background) and the possible occurrence of serial entrepreneurship process within nascent entrepreneurs. Findings are described in the following elaboration.

We first conducted validity test to measure the validity of each question in our research instrument/questionnaire by using Pearson correlation. As the rule in Pearson correlation, the coefficients are ranging between +1 and -1 , where 1 is total positive linear correlation, 0 is no linear correlation, and -1 is total negative linear correlation. From the statistical calculation using Pearson correlation that we have undertaken, 
TABLE 3: Sample Profile (Business Profile).

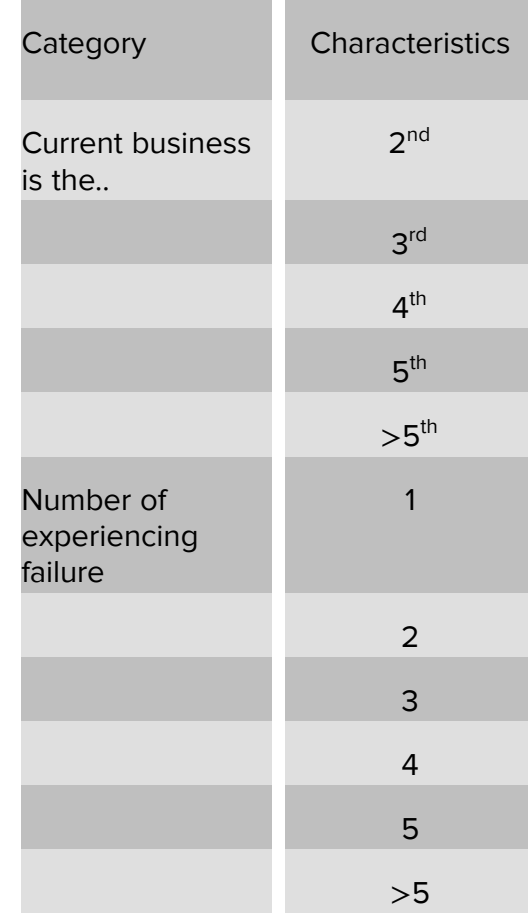

Source: Survey data, processed

\begin{tabular}{|c|}
\hline $\begin{array}{l}\text { Number of } \\
\text { Sample }\end{array}$ \\
\hline 3 \\
\hline 106 \\
\hline 50 \\
\hline 13 \\
\hline 8 \\
\hline 109 \\
\hline 47 \\
\hline 18 \\
\hline 4 \\
\hline 1 \\
\hline 1 \\
\hline
\end{tabular}

\begin{tabular}{|c|}
\hline Percentage (\%) \\
\hline 1.7 \\
\hline 58.9 \\
\hline 27.8 \\
\hline 7.2 \\
\hline 4.4 \\
\hline 60.6 \\
\hline 26.1 \\
\hline 10.0 \\
\hline 2.1 \\
\hline 0.6 \\
\hline 0.6 \\
\hline
\end{tabular}

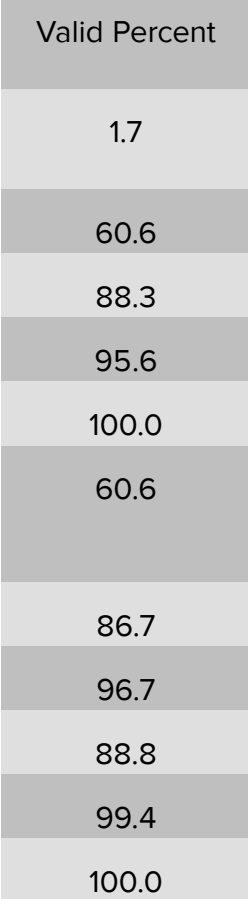

we found the range of coefficients between 0.642 and 0.799 for eight questions in the variable of entrepreneurial failure. We then concluded that each question in our research instrument which is related to the variable of entrepreneurial failure is valid. In terms of outcomes of learning which contains sixteen questions, we also found that each question is also valid. We found the coefficient of Pearson correlation is ranging between 0.446 and 0.704 . From twenty questions in the construct of error detection, we found the Pearson correlation coefficient ranging from 0.325 to 0.586 . This coefficients also indicate that each question in the construct of error detection in this study is valid. Meanwhile, in the construct of error correction which consists of twelve questions, we also concluded that each question in the questionnaire is valid. The range of coefficients of the Pearson correlation for this construct is in between 0.366. and 0.741. From all of the findings, we further conclude the all questions of the questionnaire for all research constructs in our study are valid.

The next statistical protocol that we have undertaken during the data analysis is measuring the reliability of each question from all constructs of the study. Using the Cronbach's alpha as the main measurement, we found the coefficients of Cronbach's alpha for each question as in the table 4.

Our findings suggest that the reliability test for each construct of the study is ranging from 0.788 (error correction) to 0.895 (outcomes of learning). We conclude that all 
TABLE 4: Reliability Statistics of the Questions in the Research Instrument.

\begin{tabular}{|l|l|} 
No & $\begin{array}{l}\text { Constructs/Variables of the } \\
\text { Study }\end{array}$ \\
\hline 1 & Entrepreneurial failure \\
\hline 2 & Outcomes of learning \\
\hline 3 & Error detection \\
\hline 4 & Error correction
\end{tabular}

\begin{tabular}{c} 
Number of \\
Questions \\
\hline 8 \\
16 \\
\hline 20 \\
\hline 12 \\
\hline
\end{tabular}

\begin{tabular}{c} 
Cronbach's alpha \\
\begin{tabular}{c}
0.877 \\
0.895 \\
0.815 \\
0.788 \\
\hline
\end{tabular} \\
\hline
\end{tabular}

Source: Survey data, processed

questions in the questionnaire of the study is reliable, and therefore we can proceed to the next step of statistical protocol, i.e. to test the hypotheses of the study as has been figured in Figure 2.

The next statistical protocol that we conducted in this paper is the hypotheses testing. For this purpose, we first examined the relationship between entrepreneurial failure and possible outcomes of failure in terms of learning, which is shown in table 5.

TABLE 5: The Relationship between Entrepreneurial Failure and the Positive Outcomes of Failure in terms of Learning.

\begin{tabular}{|c|c|c|c|c|c|c|}
\hline \multicolumn{7}{|c|}{ ANOVA $^{a}$} \\
\hline \multicolumn{2}{|c|}{ Model } & \multirow{2}{*}{$\begin{array}{c}\text { Sum of } \\
\text { Squares } \\
1285.967\end{array}$} & \multirow{2}{*}{$\begin{array}{l}\mathrm{df} \\
1\end{array}$} & \multirow{2}{*}{$\begin{array}{c}\text { Mean } \\
\text { Square } \\
1285.967\end{array}$} & \multirow{2}{*}{$\begin{array}{c}F \\
23.509\end{array}$} & \multirow{2}{*}{$\begin{array}{l}\text { Sig. } \\
.000^{b}\end{array}$} \\
\hline 1 & Regression & & & & & \\
\hline & Residual & 9736.894 & 178 & 54.702 & & \\
\hline & Total & 11022.861 & 179 & & & \\
\hline
\end{tabular}

a. Dependent Variable: Outcomes of failure in terms of Learning

b. Predictors: (Constant); Entrepreneurial Failure

Table 5 shows that the Sig. value of the relationship between entrepreneurial failure and possible outcomes of failure in terms of learning is 0.000 . As the rule of the significant value, the value analysis of 0.000 which is $<0.05$ is considered as significant. We therefore conclude that entrepreneurial failure significantly influences possible outcomes of failure in terms of learning.

The second hypotheses testing of this study is to measure the relationship between entrepreneurial failure and the error detection ability of nascent entrepreneurs after they have experienced failures. The finding of our study regarding this, is shown in the table 6.

As in the table 6, the Sig. value of the relationship between entrepreneurial failure and the ability for error detection by nascent entrepreneurs after they have experienced 
TABLE 6: The Relationship between Entrepreneurial Failure and Error Detection of the Coming Failures.

\begin{tabular}{|c|c|c|c|c|c|c|}
\hline \multicolumn{7}{|c|}{ ANOVA $^{a}$} \\
\hline \multicolumn{2}{|c|}{ Model } & Sum of & df & Mean & $\mathrm{F}$ & Sig. \\
\hline \multirow[t]{3}{*}{1} & Regression & 5040.149 & 1 & 5040.149 & 68.171 & $.000^{b}$ \\
\hline & Residual & 13160.163 & 178 & 73.933 & & \\
\hline & Total & 18200.311 & 179 & & & \\
\hline
\end{tabular}

a. Dependent Variable: Error detection

b. Predictors: (Constant): Entrepreneurial failure

failure is 0.000 . As the rule of the significant value, the value analysis of 0.000 which is $<0.05$ is considered as significant. We therefore conclude that entrepreneurial failure significantly influences the error detection ability of nascent entrepreneurs after they have experienced failure.

The next task of the study in this paper is to examine and to measure the relationship between entrepreneurial failure and the error correction ability of nascent entrepreneurs after they have experienced failures. We found this relationship as shown in the table 7.

TABLE 7: The Relationship between Entrepreneurial Failure and Error Correction of the Coming Failures.

\begin{tabular}{|c|c|c|c|c|c|c|}
\hline \multicolumn{7}{|c|}{ ANOVA $^{a}$} \\
\hline \multicolumn{2}{|c|}{ Model } & \multirow{2}{*}{$\begin{array}{l}\text { Sum of } \\
\text { Squares } \\
214,885\end{array}$} & \multirow{2}{*}{$\begin{array}{l}\text { df } \\
1\end{array}$} & \multirow{2}{*}{$\begin{array}{c}\text { Mean } \\
\text { Square } \\
214,885\end{array}$} & \multirow{2}{*}{$\begin{array}{c}F \\
10,485\end{array}$} & \multirow{2}{*}{$\begin{array}{l}\text { Sig. } \\
, 001^{b}\end{array}$} \\
\hline 1 & Regression & & & & & \\
\hline & Residual & 3648,092 & 178 & 20,495 & & \\
\hline & Total & 3862,978 & 179 & & & \\
\hline
\end{tabular}

a. Dependent Variable: Error correction

b. Predictors: (Constant): Entrepreneurial failure

We found from the table 7 that the Sig. value of the relationship between entrepreneurial failure and the ability for error correction by nascent entrepreneurs after they have experienced failure is 0.001 . As the rule of the significant value, the value analysis of 0.001 which is $<0.05$ is considered as significant. We therefore conclude that entrepreneurial failure significantly influences the error correction ability of nascent entrepreneurs after they have experienced failures.

The last task of the study in this paper is to examine whether the demographic profile of our sample contributes to the number of entrepreneurial failure experienced by nascent entrepreneurs. To do this task, we conducted a simple descriptive analysis by using the cross tabulation analysis to show the level of education of our sample and 
the number of entrepreneurial failure that they have experienced. The finding is shown in the table 8.

TABLE 8: The Relationship between Level of Education and Number of Failures.

\begin{tabular}{|c|c|c|c|c|c|c|c|c|}
\hline & & \multicolumn{6}{|c|}{ Number of failures } & \multirow[t]{2}{*}{ Tota } \\
\hline & & 1 & 2 & 3 & 4 & 5 & 6 & \\
\hline \multirow[t]{3}{*}{ Level of Education } & 2 & 0 & 1 & 0 & 0 & 0 & 0 & 1 \\
\hline & 3 & 37 & 11 & 3 & 1 & 0 & 0 & 52 \\
\hline & 4 & 72 & 35 & 15 & 3 & 1 & 1 & 127 \\
\hline \multicolumn{2}{|l|}{ Total } & 109 & 47 & 18 & 4 & 1 & 1 & 180 \\
\hline
\end{tabular}

2 = Junior high school

$3=$ Senior high school

$4=$ Undergraduate

The finding in table 8 suggests that the vast majority of our sample who have experienced failure are those who are having undergraduate/bachelor education. Table 8 also suggests that the category of this sample is found as the most resilience one, since around half of the failed then re-started their business (look at the composition from the $1^{\text {st }}$ failure to the $2^{\text {nd }}$ failure, and from the $2^{\text {nd }}$ failure to the $3^{\text {rd }}$ failure in the category of $3 /$ undergraduate). However, in the $4^{\text {th }}$ failure the number the failed drastically decreases.

The same tendency also happens to those who are categorized as senior high school graduates, in which the number of failure tend to decrease starting from the $2^{\text {nd }}$ failure. We believe that this indicates one thing: the occurrence of the process of serial entrepreneurship, in which nascent entrepreneurs already achieve entrepreneurial success after they experienced two to three times failure during their entrepreneurial journey and process

\section{Discussion}

We begin the discussion of the study by convincedly saying that no single entrepreneurs would like to fail -- or even, no entrepreneurs have an intention to get fail in their business. However, many stories and evidences showed us that the failure has often hit entrepreneurs, especially nascent entrepreneurs. Therefore, we view that the failure is in one package of entrepreneurial process and journey experienced by entrepreneurs. Our opinion is backed up by the finding of the study regarding the anatomy of entrepreneurs 
from [19] who stressed that entrepreneurs will usually experience two to three times failure before they reach success in their business.

The first major finding shows that there is a significant influence between entrepreneurial failure and the possible outcomes of failure in terms of learning. From analysis to the descriptive statistics related to this matter, it is known that the majority of the respondents revealed that they experience [a] strengthening capacity and competency in soft-skills, for example negotiation, presenting business ideas, self-confidence, communication skills, and how to develop alternative decision, [b] strengthening capability in managing financial matters, and $[\mathrm{c}]$ getting more supports from the closest social environment, i.e. family, as the major learning outcomes after they have experienced entrepreneurial failure. As our previous study (see [20]), we found the problems of soft-skills and managing financial resources are two major causes that have contributed to entrepreneurial failure experienced by nascent entrepreneurs. This also in line with the opinion from [14] who previously said that entrepreneurial failure comes from the deterministic factors of individuals, in which the low level of competency and capacity in managing the business is one of the major source. A low supportive social environment is also considered as the cause of entrepreneurial failure. Following [4] the low support from closest social environment, especially family, can be seen and categorized as one of the voluntaristic factor that cause entrepreneurial failure.

Finding of this study is a clear sign that the sources and causes of entrepreneurial failure, in the same time, will be used by nascent entrepreneurs as the basic knowledge to learn something for the future. Failure experiences are used as the source of learning and to gain knowledge, so that they will not get trapped into the same mistakes if they re-start their business in the near future. Therefore, from the theory of learning point of view, entrepreneurial failure will increase nascent entrepreneurs' [a] cognitive strategy, in which they will be able to memorize and think by using improved internal organized skills, and [b] improvement in attitude, [21]. Finding of this study also demonstrates of what [22] mentioned, that learning is produced from exercises and other types/forms of experience, which has three criteria: [a] learning that involves change, [b] continuous learning, and $[\mathrm{c}]$ learning from/through experiences. Learning from failure is considered as sourced from/through experiences. The

The study also proves that entrepreneurial failure has significant relationship with the ability to detect errors in business operation. From twenty construct of questions asking in the questionnaire, the majority of samples said that they can detect the most errors related to [1] financial and resources efficiency, [2] ineffective promotion activities, and [3] managing business in the traditional way -- as the sources of error in their 
business which should be avoided in the future. Error detection is also related to the awareness raised within and inside failed nascent entrepreneurs that those three are the majority problems they had in managing the business. As [15], entrepreneurial learning is triggered by the negative feedback, expressed in undesirable or unexpected outcomes of certain actions, in which the entrepreneur can improve their ability to detect errors for their next ventures. If we analyze responses from the respondents, those three detected major errors are the most typical errors that happened in micro, small and medium scale enterprises' (MSME) businesses in the context of study. For many years, inefficiency in managing financial and resources as well as traditional business and management system are always identified and recognized as the two weakest side of MSME in the context of study.

In terms of error correction, the study also shows that the entrepreneurial failure will significantly influence the correction of errors by nascent entrepreneurs. This means that failure will improve/increase the ability and capacity of nascent entrepreneurs to make error correction for their existing business or for businesses that they restarted. Descriptive statistics regarding error correction in this study show that the majority of the respondents believe that the most error correction actions that they have made are related to [a] strengthening and improving personal characters that would be beneficial for business, [b] carefully select business partners, and [c] improving soft-skills in business. Opinion and overview from respondents of the study clearly indicated that the awareness they established to detect error in their business is used as the basis to undertake corrective actions, which are mainly unrelated with the knowledge in business and management. We can also see that the corrective actions undertaken by nascent entrepreneurs would need highly self-initiatives from them, since personal characters, soft-skills and selecting business partner do not become the focus in business and management fields in the majority of business and management modules, workshop etc.

The above mentioned findings and analysis have given us directions related to the novelty of this study, i.e. by empirically proves that the entrepreneurial failure could positively influence the creation of learning within individuals/nascent entrepreneurs. Other novelty of this study is related to its ability to highlight details of learning forms and learning mechanisms that can be absorbed by nascent entrepreneurs after they have experienced entrepreneurial failure. We believe and view that those novelties would be useful and beneficial for the research in entrepreneurship, since many researches and studies in this topic could not clearly point out what kind and what type of learning 
experience that can be absorbed by nascent entrepreneurs after they have experienced failure.

The last analysis in this study is related to the relationship between demographic profile of the respondents (particularly their education background) and number of entrepreneurial failures experienced by nascent entrepreneurs. An important finding of this study reveals that there is a tendency of the process of serial entrepreneurship occurred to the respondents in the context of study. It is proven that for every level of respondents' education, the rate of failure is lower in every re-started business. The majority of respondents will experiencing failures during their first and second ventures, but the failure rate significantly decreases during the third, the fourth and the fifth restarted ventures. We can see here that from the second entrepreneurial failure, there is a probability of entrepreneurial success achieved by nascent entrepreneurs. This further means that there is a bigger probability for nascent entrepreneurs to reach success once they have experienced two times failure, and re-start their third ventures. If we look at the study from [19] regarding the anatomy of entrepreneurs, this finding confirms that entrepreneurial success is usually achieved by entrepreneurs in the second or in the third ventures. So, the serial entrepreneurship process experienced by nascent entrepreneurs will be ended with success after they started two or three failed ventures. This finding is a major and important confirmation to the opinion from [19], especially from the context of nascent entrepreneurs in the developing countries, in which the context of this study is categorized as one of them.

\section{Conclusion}

This study clearly indicates and concludes that entrepreneurial failure has significant relationship to the creation of entrepreneurial learning process and experience. We argued that entrepreneurial failure cannot be merely viewed as the negative experiences for nascent entrepreneurs. Nascent entrepreneurs can gain many experiences which can be further used as the basis to establish knowledge through the learning process from failure.

This study also concludes that the learning forms in terms of [a] personal character building, $[\mathrm{b}]$ personal soft-skills development, $[\mathrm{c}]$ managing financial and other resources efficiently, [d] how to switch management of the business from traditional to a modern way, $[e]$ business promotion, and [f] selecting business partners are the most recognizable learning experiences from failure that have been identified by nascent 
entrepreneurs, which unfortunately cannot be offered as the focuses of skills development by the majority of the business and management education programs, workshops, trainings etc. Other important conclusion is related to the fact that the serial entrepreneurship matters in achieving entrepreneurial success.

Therefore, this study implies that there should a scheme and intervention for strengthening learning skills through experience for nascent entrepreneurs. Business and management programs, workshops, trainings etc. should switch their focus and attention in delivering their subjects, i.e. by equipping participants with skills that are sourced from their own experiences to learn. The main and important focuses can be directed to the personal experiences of the participants in developing character and capacity building, as well as personal soft-skills development.

\section{Conflict of Interest}

The authors have no conflict of interest to declare.

\section{References}

[1] Besra, E., Rahman, H., \& Nurhayati, N., (2018). How Do We Perceive Failure? Introducing the Integrative Model of Entrepreneurial Failure, in Proceedings of the 2nd International Conference on Management and Entrepreneurship (I-COME). Yogyakarta-Indonesia, Universitas Kristen Petra.

[2] Smida, A. \& Khelil, N. (2010). Repenser l'échec entrepreneurial des petites entreprises émergentes. Proposition d'une typologie s'appuyant sur une approche intégrative. Revue Internationale P.M.E.: économie et gestion de la petite et moyenne entreprise, Vol. 23(2), pp. 65-106

[3] Rahman, H., Besra, E., \& Nurhayati, N., (2018). Psycho-Economic Phenomenon, Opportunistic Behaviour and Entrepreneurial Failure, in Proceeding of the 3rd Global Conference on Business, Management and Entrepreneurship (GCBME), BandungIndonesia, Universitas Pendidikan Indonesia.

[4] Singh, S., Corner, P, \& Pavlovich, K., (2015). Failed, not finished: A narrative approach to understanding venture failure stigmatization. Journal of Business Venturing, Vol. 30(1), pp. 150--166.

[5] Yamakawa, Y., \& Cardon, M. S. (2015). Causal ascriptions and perceived learning from entrepreneurial failure. Small Business Economics, Vol. 44, pp. 797-820. 
[6] Jenkins, A. S., Wiklund, J., \& Brundin, E., (2014). Individual responses to firm failure: Appraisals, grief, and the influence of prior failure experience. Journal of Business Venturing, Vol. 29, pp. 17-33

[7] Ucbasaran, D., Westhead, P., Wright, M., \& Flores, M. (2010). The nature of entrepreneurial experience, business failure and comparative optimism. Journal of Business Venturing, Vol. 25, pp. 541-555.

[8] Mantere, S., Aula, P., Schildt, H. \& Vaara, E., (2013). Narrative attributions of entrepreneurial failure. Journal of Business Venturing, Vol. 28, pp.459-473.

[9] Mueller, B., \& Shepherd, D. A. (2012). Learning from Failure: How Entrepreneurial Failure Aids in the Development of Opportunity Recognition Expertise, Frontiers of Entrepreneurship Research, Vol. 32(6), Article No. 6.

[10] Atsan, N. (2016). Failure Experiences of Entrepreneurs: Causes and Learning Outcomes, Procedia - Social and Behavioural Sciences, Vol. 235, pp. 435 -- 442

[11] Minniti, M., \& W. Bygrave. (2001). A dynamic model of entrepreneurial learning. Entrepreneurship Theory and Practice, Vol. 25(3): pp. 5--16.

[12] Lee, J., \& Miesing, P. (2017). How entrepreneurs can benefit from failure management?, Organizational Dynamics, Vol. 46, pp. 157---164

[13] Liu, Y., Li, Y., Xiling, H., \& Zhang, Y. (2019). Narcissism and learning from entrepreneurial failure, Journal of Business Venturing, Vol. 34, pp. 496-512

[14] Mellahi, K., \& Wilkinson, A. (2004). Organizational failure: a critique of recent research and a proposed integrative framework, International Journal of Management Reviews, Vol. 5, pp. 21-41.

[15] Petkova, A.P., (2008). A theory of entrepreneurial learning from performance errors, International Entrepreneurship and Management Journal, Vol. 5(4), pp. 345-367

[16] Cope, J., (2005). Toward a dynamic learning perspective of entrepreneurship. Entrepreneurship Theory and Practice, Vol. 29(4). pp. 373--397.

[17] Cope, J., (2011). Entrepreneurial learning from failure: An interpretative phenomenological analysis. Journal of Business Venturing, Vol. 26(6). pp. 604--623.

[18] Cope, J., (2003). Entrepreneurial learning and critical reflection discontinuous events as triggers for 'higher-level' learning. Management Learning, Vol. 34(4). pp. 429--450.

[19] Wadhwa, V., Aggarwal, R., Holly. H., \& Salkever, A., (July 2009). Anatomy of an Entrepreneur: Family Background and Motivation, The Ewing Marion Kauffman Foundation Research Report.

[20] Rahman, H., Besra, E., \& Nurhayati, N., (2019). The Mediating Effect of Emotive Factor on the Constructs that Influence Entrepreneurial Failure, Development Research of Management, Vol. 14(1), pp. 1-20. 
[21] Gagne, R. (1985). The Conditions of Learning. New York, NY: US, Holt, Rinehart \& Winston

[22] Schunk, D. H. (2012). Learning theories: an educational perspective, Boston, MA: US, Pearson Education, Inc. 